\title{
Adsorptive Removal of Chromium (VI) using Silver Nanoparticles Synthesized Via Green Approach with the Extract of Moringa stenopetala
}

\author{
WENDIMAGEGN TAGESSE ${ }^{1,2 *}$ and BRHANE HAILE ${ }^{1,3}$ \\ 'Dilla University, College of Natural and Computational Sciences, Department of chemistry, \\ P. O. Box 419, Dilla, Ethiopia. \\ 2Dilla University, University Industry Linkage Coordinator, P. O. Box 419, Dilla, Ethiopia. \\ ${ }^{3}$ Dilla University, Reform Office Coordinator, P. O. Box 419, Dilla, Ethiopia. \\ *Corresponding author E-mail: Wendimagegnt@ du.edu.et, brhanehai21@ gmail.com
}

http://dx.doi.org/10.13005/ojc/370217

(Received: December 27, 2021; Accepted: March 07, 2021)

\begin{abstract}
In the current study, the potential sorption of $\mathrm{Cr}(\mathrm{VI})$ ions through a zero-valent silver nanoparticle synthesized by a green approach has been studied. The objective of this research was to remove $\mathrm{Cr}(\mathrm{VI})$ from aqueous solution using zero-valent silver nanoparticles synthesized from Moringa stenopetala leaves extract. The synthesized silver nanoparticles were characterized using X-ray diffractometer and UV-Visible spectrophotometer. The grain size of nanoparticles was found to be 19.5 $\mathrm{nm}$ confirming the crystalline structure of the mesosphere and showed the maximum absorption at $419 \mathrm{~nm}$. In order to determine parameters that influence the adsorption mechanism, batch adsorption experiments have been conducted. Results obtained for removal of $\mathrm{Cr}(\mathrm{VI})$ ions showed that efficiency of removal improved as adsorbent dosage increased until the equilibrium point reached at 50 minutes. However, as the $\mathrm{pH}$ of the solution increased from 1 to 8 and as the Preliminary concentration of $\mathrm{Cr}$ increased, removal efficiency decreased. Adsorption isotherms were investigated by applying the models of Langmuir and Freundlich. The Freundlich isotherm can better explain the removal of $\mathrm{Cr}(\mathrm{VI})$ ions, offering correlation coefficient values greater than the Langmuir isotherm model. Adsorption kinetics regression results studied by the pseudo-first and second-order models moreover proved that a pseudo-first-order was further accurately represented by the adsorption kinetics. In order to alleviate wastewater problems, the implementation of this approach is able to cost-effective, eco-friendly and publicly viable. To improve its removal effectiveness and compare it with other adsorbents, additional study on surface modification of this adsorbent is required.
\end{abstract}

Keywords: Adsorption isotherm, Green Synthesis, Hexavalent chromium, kinetics, Moringa stenopetala, Silver nanoparticle.

\section{INTRODUCTION}

\section{Background of the study}

Nanotechnology is a technology that is one of the world's most innovative approaches.
Nanotechnology describes a number of nanometerscale technologies that range from individual atoms or molecules to around 100 nanometers. The noble metal nanoparticles such as $\mathrm{Ag}, \mathrm{Au}, \mathrm{Pd}$, and Pt are the focus of attention today because of their strong

This is an Open Access article licensed under a Creative Commons license: Attribution 4.0 International (CC- BY). Published by Oriental Scientific Publishing Company @ 2018 
optical absorption in the visible region caused by the collective excitation of free-electron gas. ${ }^{2}$ Biosynthesis of nanoparticle is eco-friendly, timeefficient and cost-effective. More significantly, the biosynthesized NPs on their surface are free of toxic materials. Green production of AgNPs with biological extract is a healthy as well as advantageous way to synthesize metallic nanoparticle since it is readily accessible. In addition, plant extract can serve as both a reducing and stabilizing agent during the synthesis of AgNPs. Photochemicals such as flavonodis, terpenodis, terpenes, flavones, phenolics, polysaccharides, saponins, tannins and alkaloids have been used for the synthesis of AgNPs. ${ }^{3}$ These photochemicals contain hydroxyl, aldehyde, ketone, carboxyl, and amino functional groups capable of reducing $\mathrm{Ag}^{+}$ions. ${ }^{3}$

Nanomaterials have been under intensive study over the last decade and effectively implemented in several areas such as, catalyst fabrication, medication, artificial intelligence, and life science. Due to large specific surface areas, nanomaterials show high adsorption abilities, reactivity, and freely move in solution. It has been documented that heavy metals, organic contaminants, inorganic anions, and bacteria are successfully removed by different kinds of nanomaterials. Nanomaterials demonstrate great assurance for practical use in water-based and industrial effluent treatment on basis of frequent studies. ${ }^{4}$ Toxic metals like $\mathrm{Cu}, \mathrm{Pb}$, $\mathrm{Zn}, \mathrm{Ni}, \mathrm{Hg}, \mathrm{Cr}$, etc present in the effluents of chemical industries like finishing and electro-plating, mining and tanneries are among the chief pollutants of surface and groundwater which harm both the fauna and flora in aquatic systems and are detrimental to human health. Relatively costy techniques including exchange adsorption, solvent extraction and filtration have been used for removal of heavy metals. A benefit of the adsorption approach is cost effective and recyclable. ${ }^{5,6}$

Nowadays, zero-valent nanoparticles of metals, nanoparticles of metal oxides, carbon nanotubes (CNTs), and nanocomposites are widely researched nanomaterials for water and wastewater treatment. However, the objective of this study is to evaluate the removal potential of zero-valent silver nanoparticles synthesized from leaves of Moringa stenopetala as mediator for the removal of hexavalent Chromium from aqueous solution. No literature data are available on removal of $\mathrm{Cr}(\mathrm{VI})$ ions by silver nanoparticle synthesized with Moringa stenopetala leaves.

\section{EXPERIMENTAL}

\section{Moringa stenopetala leaves Collection}

Moringa stenopetala leaves from the Dilla University compound, Ethiopia, were collected. To remove any particulate matter, the collected leaves were thoroughly washed under tap water and then washed with distilled water. The leaves were then oven dried at $50^{\circ} \mathrm{C}$ and cut into tiny pieces.

\section{Solvent Extraction}

Moringa stenopetala extract was prepared by boiling $20 \mathrm{~g}$ Moringa stenopetala leaf at $60^{\circ} \mathrm{C}$ in $0.1 \mathrm{~L}$ of distilled water for 5 minute. The mixture was then filtered and the filtrate was kept at $4^{\circ} \mathrm{C}$ until used as reducing and capping agent during the synthesis of Ag nanoparticles.

\section{Green synthesis of AgNPs}

The synthesis of AgNPs was performed by the method of bottom-up approaches starting with a precursor of metal salt (dissolved in a solvent) that is reduced in a chemical reaction and the NPs are formed by a nucleation process followed by a cluster growth. ${ }^{7} 2 \mathrm{~mL}$ of Moringa stenopetala leaves extract was taken for the synthesis of zero valent silver nanoparticles and added to $20 \mathrm{~mL}$ of $\mathrm{AgNO}_{3}(1 \mathrm{mM})$. The color of the solution changed to dark brown. Finally, the solution was stirred for $40 \mathrm{~min}$ followed by centrifuging for $20 \mathrm{~min}$ at 150 rpm and washed five times to remove residues of $\mathrm{Ag}^{+}$ions. This experiment was performed at room temperature. The presence of the dark brown color confirmed the production of $\mathrm{Ag}$ nanoparticles. The centrifuged $\mathrm{Ag}$ nanoparticles were then used for further experiment. ${ }^{8}$

\section{Preparation of working standard solutions}

$\mathrm{Cr}(\mathrm{VI})$ stock solution $(1000 \mathrm{mg} / \mathrm{L})$ was first prepared from potassium dichromate (99.9 percent, $\mathrm{BDH}$ ) by dissolving $2.28 \mathrm{~g} \mathrm{k}_{2} \mathrm{Cr}_{2} \mathrm{O}_{7}$ in deionized water, thoroughly mixed and the solution was diluted to the mark of $1 \mathrm{~L}$ standard bottle. An intermediate solution of $100 \mathrm{ppm}$ hexavalent chromium was then prepared by taking $50 \mathrm{~mL}$ of the stock solution and diluting it through deionized water into $500 \mathrm{~mL}$ standard flask. For method 
calibration, six working standard solutions with different concentrations of 1.0, 3.0, 5.0, 7.0, 9.0 and $11 \mathrm{ppm}$ were prepared. (Figure. 1).

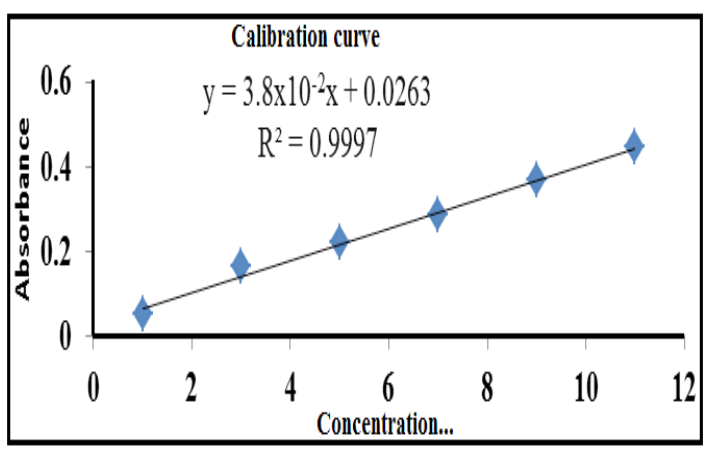

Fig. 1. Method calibration curve

\section{Removal experiments}

The batch experiments were carried out by adding $30 \mathrm{~mL}$ of $\mathrm{Cr}(\mathrm{VI})$ solution into $250 \mathrm{~mL}$ standard flasks at the desired adsorbent dose, $\mathrm{pH}$, and contact time at room temperature. The solutions were shaken using electronic mechanical shaker for a definite period of time. Effect of adsorbent dose (25 to $125 \mathrm{mg}$ ), contact time (5 to $60 \mathrm{~min}$ ), $\mathrm{pH}$ (1 to 8), initial concentration of adsorbate (1, 3, $5,7,9$ and $11 \mathrm{mg} / \mathrm{L}$ ) were studied by continuous variation method at $120 \mathrm{rpm}$ agitation speed. The $\mathrm{pH}$ of the $\mathrm{Cr}(\mathrm{VI})$ containing solution was adjusted using $1 \times 10^{-1} \mathrm{~mol} \mathrm{~L}^{-1}$ hydrochloric acid or $1 \times 10^{-1}$ mol L-1 sodium hydroxide.

The $\operatorname{Cr}(\mathrm{VI})$ concentrations in the test solutions were controlled by UV-Vis-spectrometer at $540 \mathrm{~nm}$. Experiments were carried out in two parameter options to confirm the observed effects instead of taking triplicate measurements. The percentage of the removal of $\mathrm{Cr}(\mathrm{VI})$ from aqueous solution was estimated using the formula: ${ }^{6}$

$\mathrm{R} \%=\frac{\mathrm{C}_{0}-\mathrm{C}_{\mathrm{t}}}{\mathrm{C}_{\mathrm{o}}} \times 100$

\section{Evaluation of adsorption efficiency}

Adsorption isotherm is very interesting to consider and describe how the solutes interact with the adsorbent. To illustrate the removal process, the adsorption data were fitted to the two commonly used isotherm models namely: Langmuir and Freundlich given in equation (3) and (4) respectively. Lagergren's pseudo first-order model in equation (5) and pseudo-second-order model in equation (6) were used to fit the kinetic adsorption data, and all of the kinetic parameters for chromium (VI) ion were determined from their graphs. The amounts of hexavalent chromium adsorbed on the $\mathrm{Ag}$ nanoparticles were represented by the Adsorption capacity ( $\mathrm{q}, \mathrm{mg} / \mathrm{g}$ ) and calculated as shown in equation (2):

$\mathrm{q}_{\mathrm{e}}=\frac{\left(\mathrm{C}_{0}-\mathrm{C}_{\mathrm{e}}\right) \mathrm{xV}}{\mathrm{m}}$

Where $\mathbf{m}$ is adsorbent mass expressed by $\mathrm{g}, \mathrm{V}$ is solution volume in $\mathrm{L}$ and $\mathrm{C}_{\mathrm{o}}$ and $\mathrm{C}_{\mathrm{e}}$ are the original and equilibrium $\mathrm{Cr}(\mathrm{VI})$ amounts, expressed by $\mathrm{mg} \mathrm{L}^{-1}$, respectively. Using the statistical applications Origin pro 8 and Microsoft excel 2007, plots and linear regression were performed. Recorded data from linear regression contains coefficient value of $\mathrm{R}^{2}$ correlation. ${ }^{9}$

$$
\begin{aligned}
& \operatorname{lnq_{\mathrm {e}}}=\ln \mathrm{K}_{\mathrm{F}}+\frac{1}{\mathrm{n}} \ln \mathrm{c}_{\mathrm{e}} \\
& \frac{C_{e}}{q_{e}}=\frac{1}{Q_{o} b}+\frac{C_{e}}{Q_{o}} \\
& \ln \left(\mathrm{q}_{\mathrm{e}}-\mathrm{q}_{\mathrm{t}}\right)=\ln \mathrm{q}_{\mathrm{e}}-\mathrm{K}_{1} \mathrm{t} \\
& t / q_{t}=1 / K_{2} q^{2} e+t / q_{e}
\end{aligned}
$$

\section{Characterization of Adsorbent $X$-ray diffractometer analysis}

$X$-ray diffractometer (XRD) with $2 \theta$ scope of 10-800 using CuKa X-ray source was applied to study the crystal structure and amorphous nature of the prepared zero valent silver nanoparticle. The prepared powder of AgNPs was filled into a sample holder of aluminum. X-ray diffraction analysis of the samples was carried out on a $40 \mathrm{kV}$ and 30 $\mathrm{mA}$ working diffractometer with a Cu-Ka radiation wavelength of Lambda $=1.5406 \AA$. Using Origin 8.0 software, the XRD spectra were analyzed, and the crystallite particle size was determined from the width of the peaks by taking the maximum strong pick, using Scherrer's equation formula (7). ${ }^{10}$

$D=\frac{0.9 x \lambda}{\beta x \cos \theta}$

\section{UV-Vis Spectroscopy}

The chemical reduction of monovalent silver to zero valent silver metal was controlled by determining the UV-Vis absorption spectrum of the solution containing a small aliquot of the sample in deionized water kept for four hours. ${ }^{11}$ 


\section{RESULTS AND DISCUSSIONS}

\section{Visual observation}

The reduction of $\mathrm{Ag}^{+}$ion into $\mathrm{Ag}^{0}$ metal nanoparticle upon exposure to Moringa stenopetala leaf extract resulted color change. The yellowish green suspension of Moringa stenopetala leaf extract (Fig. 2A) turned into dark brown emulsion (Fig. 2C) after the addition of $\mathrm{AgNO}_{3}$ (Fig. 2B) and $24 \mathrm{~h}$ continuous stirring at room temperature.

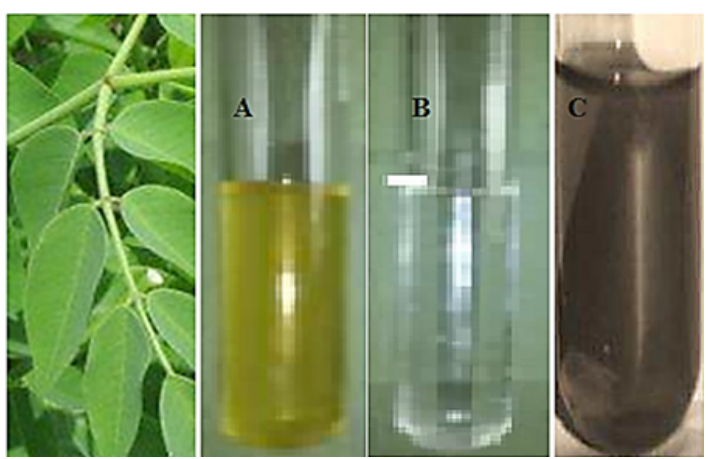

Fig. 2. (A) Yellowish green extract of M. stenopetala leaves (B) Color less $\mathrm{AgNO}_{3}$ solution. (C) Dark brown emulsion

Surface-Plasmon Resonance is responsible for the color changes in aqueous solution (Fig. 2). Synthesis mechanism of AgNPs can vary with nature of phytochemicals. However, the chief mechanism is the reduction of $\mathrm{Ag}^{+}$ions by specific functional groups. During preparation of AgNPs the possible mechanism is silver ions dispersed into the extract of Moringa stenopetala leaf after that the reaction takes place to form [Ag (Moringa stenopetala leaf extract) + complex]. In the extract there is aldehyde functional group that is used to reduce silver mono valent to silver zero valent. Therefore, AgNPs is formed while aldehyde functional group oxidized to carboxylic acid groups. The carboxylic acid groups are left in the solution but AgNPs is precipitated in the test tube, which is in agreement with Smaranika et al., ${ }^{12}$

\section{Characterization of nanoparticles $X$-ray diffractometer characterization}

Figure 3 demonstrated the XRD blueprint of Ag nanoparticle formed. The synthesized silver nanoparticle has the characteristic peaks on the pattern of AgNPs at $2 \theta$ values $34.85^{\circ}, 38.52^{\circ}$ and $44.77^{\circ}$ conforms to lattice plane at (111) and (200) of metallic silver respectively as shown in (Fig. 3). Moreover, X-ray diffractometer blueprint confirms face centered cubic structure of metallic silver and the data is correlated with international center for diffraction data (ICDD PDF2). The additional peaks at $2 \theta$ values can be approved due to the organic residues of the plant extract, which is in agreement with Saba et al.,13. According to the Scherer calculation, the grain size of the synthesized AgNPs obtained is $19.5 \mathrm{~nm}$ resulting using peak FWHM, which is matching to 111 planes. Different research works show that green synthesized NPs with particle sizes below $20 \mathrm{~nm}$ are highly reactive. ${ }^{9}$

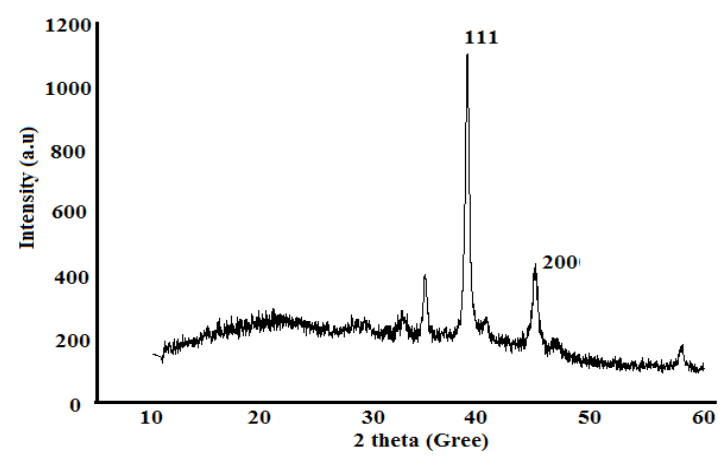

Fig. 3. XRD pattern of synthesized silver nanoparticle powder

\section{UV-Vis Spectroscopy}

The maximum absorption peak at $419 \mathrm{~nm}$ (Fig. 4A) is due to Surface Plasmon Resonance that point toward the AgNPs formation. Silver nanoparticles have free electrons so as to give the Surface Plasmon Resonance absorption band. A single Surface Plasmon Resonance band is revealed in current study that proves no agglomeration of AgNPs. It is observed that the absorption of silver nanoparticles increases as the incubation time increases to $24 \mathrm{~h}$ (Fig. 4B). The maximum attainability in the stability of AgNPs and constant absorption after at $24 \mathrm{~h}$ reaction time is observed. Abambagade and Belete have previously recorded similar outcomes. ${ }^{14}$

\section{Influence of PH}

A potential of AgNPs to remove hexavalent chromium in aqueous solution at different $\mathrm{pH}$ values $(1-8)$ is shown in (Fig. 5). All other parameters were kept constant: contact time (60 min), dosage (0.05 g) and the initial metals concentration $(5.5,11 \mathrm{mg}$ $\left.\mathrm{L}^{-1}\right)$. Adsorption of hexavalent chromium ion was maximum at lower $\mathrm{pH}$ and rapidly decreases as $\mathrm{pH}$ values rise up to 8 . Chromium (VI) can occur primarily like $\mathrm{CrO}_{4}^{-2}, \mathrm{Cr}_{2} \mathrm{O}_{7}^{-2}, \mathrm{HCrO}_{4}^{-}, \mathrm{H}_{2} \mathrm{CrO}_{4}$ and $\mathrm{H}_{2} \mathrm{Cr}_{2} \mathrm{O}_{7}$ in aqueous solutions. $\mathrm{CrO}_{4}^{-2}$ predominates at high $\mathrm{pH}$ while hydrogen chromate $\left(\mathrm{HCrO}_{4}^{-}\right)$ 
predominates at low $\mathrm{pH}$. The $\mathrm{HCrO}_{4}^{-}$form is thus inferred at low $\mathrm{pH}$ is the main type of hexavalent chromium favorable sorbed by AgNPs. Because of the addition of acid $\mathrm{H}^{+}$, the surface of the adsorbent is positively charged ions at low $\mathrm{pH}$ and this facilitates the binding of negatively charged $\mathrm{HCrO}_{4}^{-}$ions. Thus, with decreasing $\mathrm{pH}$, the adsorption of hexavalent chromium ions enhances noticeably. When the $\mathrm{pH}$ is increase, AgNPs losing surface positivity and these results in a dropping in electrostatic interaction force between adsorbent and adsorbate ion. ${ }^{15}$
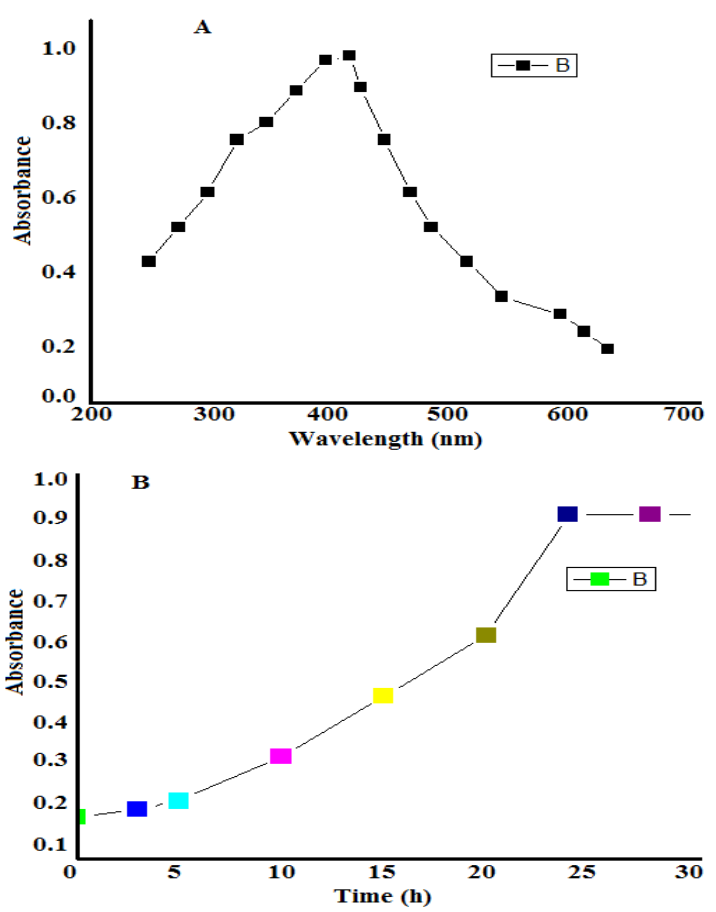

Fig. 4. (A) UV-Vis absorption spectrum of AgNPs synthesized (B) Absorbance recorded as function of incubation period

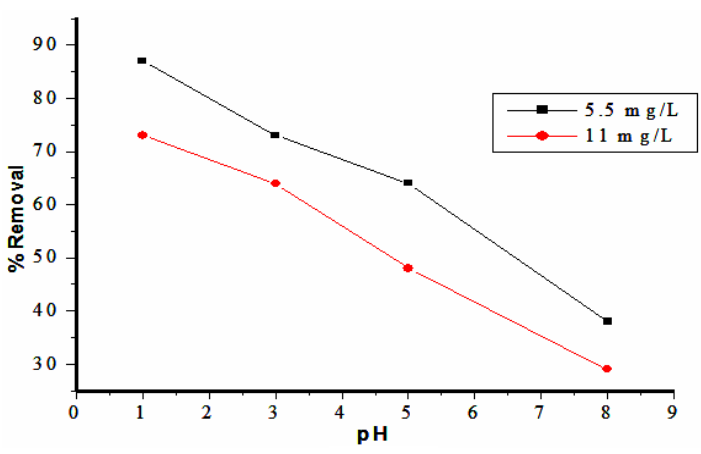

Fig. 5. pH optimization

Influence of initial concentration of hexavalent Chromium

Influence of initial concentration on hexavalent Chromium removal by AgNPs was studied at various initial concentrations ranging 1 to $11 \mathrm{mg} \mathrm{L}^{-1}$ at pH 1, contact times (60 min) and at different adsorbent dose (50 mg and $25 \mathrm{mg}$ ). The percentage removal depends primarily on the initial metal concentrations. Hexavalent chromium ions removal at different concentration as shown in (Fig. 6) that the removal percentages decrease with increases in metal ions concentrations.

Removal efficiency of $97 \%$ has been achieved using a $1 \mathrm{ppm}$ initial $\mathrm{Cr}(\mathrm{VI})$ concentration. The decrease in percentage removal with an increase in initial concentration may be due to lack of enough surface area to accommodate much more $\mathrm{Cr}(\mathrm{VI})$ ions accessible in the solution. This explanation may be supported by the knowledge that at extremely low hexavalent chromium ions, the ratio of the available surface of the adsorbents to the initial concentration of chromium is high, creating a higher chance of chromium removal. Binding sites get quickly saturated when increasing in initial chromium concentration as adsorbent dose remained constant. Hence, in case of high adsorbate concentrations the percentage removal decreases. ${ }^{16}$

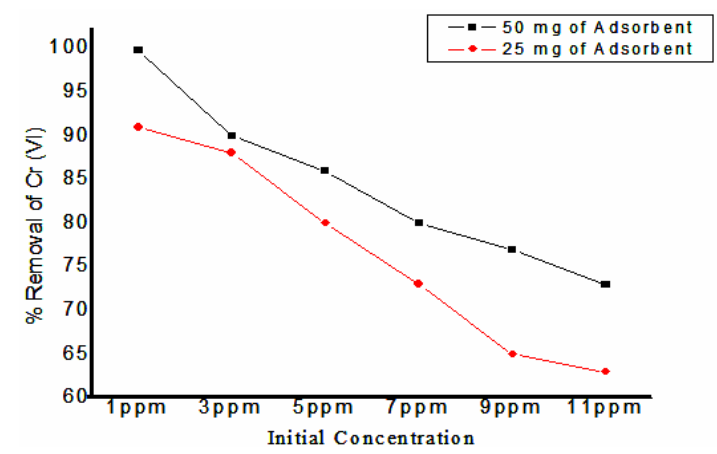

Fig. 6. Influence of initial concentration adsorption

\section{Influence of contact time}

The influence of time in $\mathrm{Cr}(\mathrm{VI})$ reduction was studied for hexavalent Chromium concentration at $5.5 \times 10^{3}$ and $11 \times 10^{3} \mathrm{Mg} \mathrm{L}^{-1}, \mathrm{pH} 1,0.05 \mathrm{~g}$ adsorbent dose, $120 \mathrm{rpm}$ stirring speed and different contact times (10-60 min), respectively. (Fig. 7). The results showed that highest percentage removal of $\mathrm{Cr}(\mathrm{VI})$ has been achieved at 50 minute. This indicates that 50 min was required to reach equilibrium for $\mathrm{Cr}(\mathrm{VI})$ removal on AgNPs. As contact time increased, no significant increment in hexavalent Chromium ion reduction from the solution was noticed. Therefore, mass transfer from a mass solution to binding sites is affected by contact time. ${ }^{9}$ 


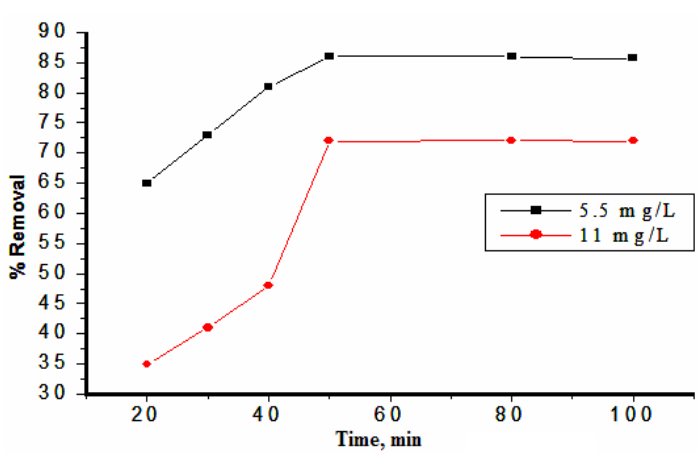

Fig. 7. The influence of contact time on hexavalent chromium adsorption

\section{Influence of dosage}

The influence of the adsorbent dose in the removal of hexavalent chromium ions should be investigated. The effect of adsorbent mass (25-125 $\mathrm{mg}$ ) on removal of hexavalent chromium at initial $\mathrm{Cr}(\mathrm{VI})$ concentrations (5.5 ppm and $11 \mathrm{ppm}$ ), at $\mathrm{pH}$ 1 and at $50 \mathrm{~min}$ of contact time was studied. The results, represented by (Fig. 8), indicated that when the amount of AgNPs increases, the hexavalent chromium removal efficiency enhances and the removal efficiency became constant at higher amounts of AgNPs. The direct relationship between adsorbent dose and adsorption efficiency is because of the fact that more exchangeable sites for chromium ions and greater surface area of AgNPs are accessible when dose of adsorbent in solution is high. ${ }^{17}$

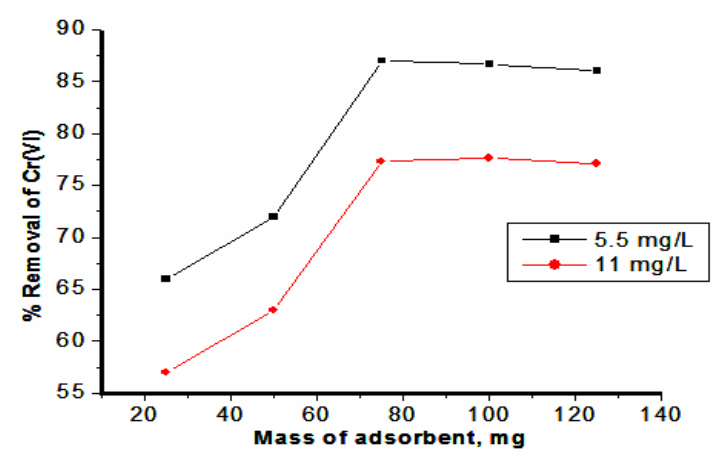

Fig. 8. Influence of dosage on adsorption

\section{Adsorption isotherm study}

The functional relation between the concentration of hexavalent chromium ions sorbed on the AgNPs surface and hexavalent chromium ions left in solution was tested with Langmuir and Freundlich adsorption isotherms. Further Langmuir isotherm analysis is able to done using the separation factor $\left(R_{L}\right)$ which is unit less immeasurable extent. The $R_{L}$ value for a favorable adsorption lies between 0 and 1 while $R_{L}$ value exceeds1 for unfavorable adsorption,
Adsorption is linear for $R_{L}=1$ and it is irreversible if $R_{L}$ $=0$. In this analysis, the separation factor $R_{L}$ is 0.844 , which explains the favorable adsorption process for removal of $\mathrm{Cr}(\mathrm{VI})$. The constants of Freundlich; $\mathrm{kf}$ and $\mathrm{n}$ cab are determined by plotting the graph between Inqe and InCe as shown in (Fig. 10). High n value (2.1) indicates that $\mathrm{Ag}$ nanoparticles are better adsorbents for aqueous solution intake of $\mathrm{Cr}(\mathrm{VI})$. The Langmuir equation in the $C_{e} / q_{e}$ versus $C_{e}$ graph is seen in (Fig. 9). The $Q_{0}$ values are obtained as 5.435 $\mathrm{mg} \mathrm{g}^{-1}$ at room temperature. The linear relationship for the Freundlich isotherm model is higher than for the Langmuir isotherm model. (Tables 1 and 2 ). ${ }^{18}$

\section{Kinetic study}

Table 1: Adsorption isotherm data

\begin{tabular}{cccccc}
\hline Absorbance & $\mathrm{C}_{\mathrm{e}}$ & $\mathrm{Q}_{\mathrm{e}}$ & $\mathrm{C}_{\mathrm{e}} / \mathrm{q}_{\mathrm{e}}$ & Lnqe & Lnce \\
\hline 0.0276 & 0.03421 & 0.5795 & 0.059 & -0.55 & -3.4 \\
0.037 & 0.282 & 1.63 & 0.173 & 0.488 & -1.3 \\
0.049 & 0.5974 & 2.642 & 0.226 & 0.972 & -0.52 \\
0.078 & 1.361 & 3.384 & 0.4022 & 1.22 & 0.31 \\
0.104 & 2.045 & 4.173 & 0.49 & 1.43 & 0.72 \\
0.139 & 2.966 & 4.821 & 0.62 & 1.6 & 1.1 \\
\hline
\end{tabular}

Table 2: Adsorption isotherm parameters for $\mathrm{Cr}(\mathrm{VI})$ removal from synthetic effluent by AgNPs

\begin{tabular}{lcccccccc}
\hline Langmuir & \multicolumn{5}{c}{ Freundlich } \\
\hline Metal & $\mathrm{Q}_{\mathrm{o}}\left(\mathrm{mg} \mathrm{g}^{-1}\right)$ & $\mathrm{b}\left(\mathrm{g} \mathrm{mg}^{-1}\right)$ & $\mathrm{R}_{\mathrm{L}}$ & $\mathrm{R}^{2}$ & $\mathrm{n}$ & $\mathrm{K}_{\mathrm{f}}\left(\mathrm{Lg}^{-1}\right)$ & $\mathrm{R}^{2}$ \\
$\mathrm{Cr}(\mathrm{VI})$ & 5.435 & 0.034 & 0.844 & 0.972 & 2.1 & 3.021 & 0.995 \\
\hline
\end{tabular}

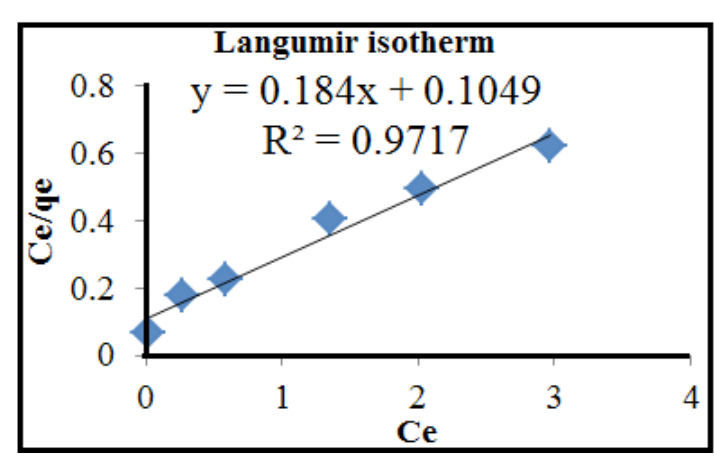

Fig. 9. Langmuir model

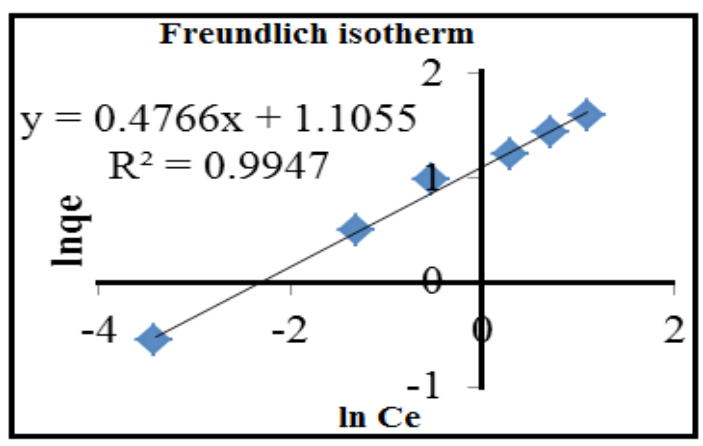

Fig. 10. Freundlich model 
Pseudo first and Pseudo-second order kinetic models were used to study $\mathrm{Cr}(\mathrm{VI})$ sorption on the surface of AgNPs. (Figs. 11 and 12) illustrate experimental data plots at different contact time for pseudo first and second order models, respectively. The pseudo first order considers that the speed at which adsorption sites are occupied is directly dependent on the number of unoccupied sites. ${ }^{19}$ The Pseudo Second Order model considers that the square of number of vacant sites on the adsorbent is affected by the speed of adsorption in metal ions. The higher values of the correlation coefficients $\left(R^{2}\right)$ and the comparative analysis of the observational adsorption capacity, qe(exp) with the measured value, qe(cal) acquired for the removal of $\mathrm{Cr}(\mathrm{VI})$ ions indicated that the pseudofirst order model was excellent than the pseudoSecond order. (Table 3 below) ${ }^{20}$

Table 3: Pseudo-first and second-order kinetics for sorption of hexavalent chromium onto AgNPs

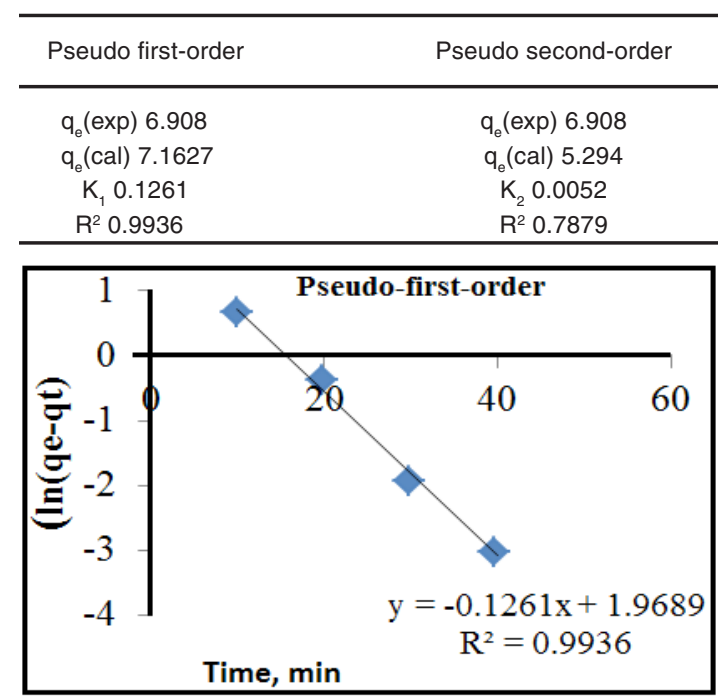

Fig. 11. Pseudo first order kinetic

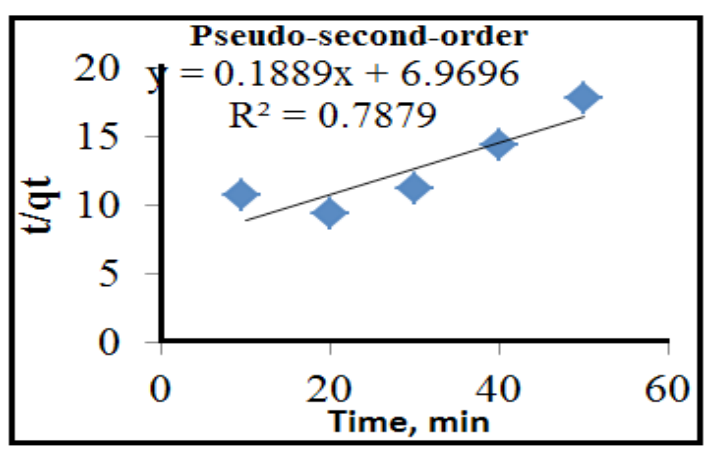

Fig. 12. Pseudo-second-order kinetic

\section{CONCLUSION}

In the current study one pot method for the production of AgNPs using Moringa stenopetala leaves extract has been reported. This approach is very quick, appropriate, less time-consuming, and environmentally friendly and can be used in a number of current applications. The green synthesis of $\mathrm{Ag}$ nanopartilces using Moringa stenopetala leave extract was successful which is mesosphere's crystalline structure having $19.5 \mathrm{~nm}$ particle size. The experimental results indicated that AgNPs were effective in water purification and environmental remediation. Parameters like influence of $\mathrm{pH}$, influence of contact time, influence of dosage and influence of hexavalent chromium concentration were optimized. Among these parameters, the most significant parameter that influences the sorption methods was established to be $\mathrm{pH}$ optimization. Two isothermal models Langmuir and Freundlich were used to model the results obtained. An equilibrium isotherm was well described by Freundlich equation, which showed that the surface is heterogeneous with $n$ values 2.1 capable of multilayer adsorption and therefore favorable adsorption has occurred. The selected adsorbent has removed $97 \% \mathrm{Cr}(\mathrm{VI})$ from the aqueous solution. The pseudo-first-order model equation can well explain the adsorption kinetics, since $R^{2}$ is greater than 0.99 at low concentration, but the pseudo-second-order model equation shows $\mathrm{R}^{2}=0.78$. In order to improve its removal effectiveness and compare it with other adsorbents, yet more experimentation on the chemical modifications of this adsorbent is needed.

\section{ACKNOWLEDGMENT}

The authors would like to thank the Dilla College of Natural and Computational Department of Chemistry for the tools and chemicals provided.

\section{Conflict of interest}

No conflict of interest was declared by the authors. 


\section{REFERENCE}

1. Kanchi, S. Environmental Analytical Chemistry., 2014, 1(2), 1-3.https://DOI: 10.4172/2380-2391.1000e102.

2. Davoud, D.; Shiva, T.; Farzane, K. Soft Nanoscience Letters., 2013, 3(4), 93-100. DOI: 10.4236/snl.2013.34017.

3. Arul Dhas, N.; Paul Raj, C.; Gedanken, A. Chem. Mater, 2018, 10(5), 1446-1452. https://doi.org/10.1021/cm9708269.

4. Shakeel, A.; Mudasir, A.; Babu Lal, S.; Saiqa, I. Journal of Advanced Research., 2016 7(1), a. 17-28 https://doi.org/10.1016/j. jare.2015.02.007.

5. Haijiao, L.; Jingkang, W.; Marco, S.; Ting, W.; Ying, B.; Hongxun, H. Advances in Materials Science and Engineering., 2016, 3, https:// doi.org/10.1155/2016/4964828.

6. Burks, T. kth royal institute of technology school of chemical science and engineering, 2016, 4, 1-76. urn:nbn:se:kth:diva-179871.

7. Rauf, M. A.; Iqbal, M. J.; Ikram, M.; Rauf, N. Adsorption Studies of $\mathrm{Ni}(\mathrm{II})$ from Aqueous Solution onto Bentonite. Soil and environmental sciences., 2003, 21(2). https:// doi.org/10.1081/TMA-120020267.

8. Ibrahim, M.; Ehab, S. Scrivener Publishing LLC., 2018, 293-319. Book chapter 10 https://doi. org/10.1002/9781119418900.ch10.

9. Khairia, M.; Al-Qahtani. Egyptian Journal of Aquatic Research., 2017, 43(4), 269-273. https://doi.org/10.1016/j.ejar.2017.10.003.

10. Workineh, M. F.; Wendimagegn, T.D.; Girmaye, Benti. Cogent Food \& Agriculture., 2020, 6, 1-14 https://doi.org/10.1080/23311932.202.1 816420.

11. Prasad, TNVKV.; Elumalai, EK. Asian
Pacific Journal of Tropical Biomedicine, 2011, 1(6), 439-442. doi: 10.1016/S2221. 1691(11)60096-8.

12. Smaranika, D.; Umesh, K.; Birendra, K. International Journal of Nanotechnology and Application., 2013, 3(2), 51-62.

13. Saba, A.; Hussein, R. International Journal of ChemTech Research., 2017, 10(3), 508-514. a.https://www.researchgate.net/ publication/316147987.

14. Abambagade, A.; Belete, Y. African Journal of Biotechnology., 2017, 16(32), 1705- 1716. https://doi.org/10.5897/AJB2017.16010.

15. Khairia, M.; Al-Qahtani. American-Eurasian Journal of Toxicological Sciences., 2016, 8, 102-109. https://doi.org/10.5829/idosi. aejts.2016.8.2.10422.

16. Mohamed, E.; Fatima, Al-T.; Ragwan, M.; Khadija, A. American Journal of Analytical Chemistry., 2015, 6, 3. DOI: 10.4236/ajac. 2015.61001.

17. Tolaymat, T.M.; El Badawy, A.M.; Genaidy, A.; Scheckel, K.G.; Luxton, T.P.; Suidan, M. Sci. Total Environ., 2010, 408(5), 999-1006. DOI: 10.1016/j.scitotenv.2009.11.003.

18. Radia, L.; Oumessaad, B.; Adh'Ya, E.; Andre, D. Adsorption Science \& Technology., 2018, 36(3-4). https://doi.org/10.1177/0263617417750739.

19. Thilagan, J.; Gopalakrishnan, S.; Kannadasan, T. International Journal of Pharmaceutical and Chemical Sciences., 2013, 2(2), 1062. https://www.researchgate.net/publication/ 288617367.

20. Hojat, V.; Sirous, A. Pourya, M. Journal of Cleaner Production., 2018, 170, 1536-1543. https://doi.org/10.1016/j.jclepro.2017.09.265. 